\title{
El camino americano de Martín en Sobre héroes y tumbas
}

Theamerican way of $M$ artin in $0 \mathrm{n}$ heroesand tombs

\section{Alejand ro H ermosilla Sán Chez}

\author{
Universidad de M urcia, Españ
}

E-mail: adler136@hotmail.com

\section{RESU MEN}

Este artículo tiene como objetivo analizar al personaje M artín de Sobre héroes y tumbas (1961), desde una perspectiva que permita comprender su recorrido vital por la novela de Sábato como un recorrido de aprendizaje de la verdad de su patria. Para ello, se incide en poner de relieve la importancia de los lugares donde comienza y termina la novela. A su vez, se pone de manifiesto la importancia de Alejandra para la posibilidad de realización del camino emprendido por M artín: el reconocimiento de la auténtica historia de Argentina y América.

Palabras claves: Argentina, Boca, Caín, destino, madre, oro, tierra.

\section{ABST RACT}

The objective of this article is to analyze $M$ artin, a character from $0 \mathrm{n}$ heroes and tombs (1961), taking a perspective that allows the reader to understand his vital passage through Sábato's novel as a journey of learning thetruth about his mother land. In order to accomplish this, the importance of those places where the novel begins and ends is emphasized. In turn, we underline the importance of Alejandra for the realization of this route taken by $M$ artin: the recognition of the authentic history of Argentina and America.

Keywords: Argentina, Boca, Cain, destiny, gold, land, mother.

Recibido: 10-11-2006. Aceptado: 30-11-2006.

O CREO que sea casual que Sábato sitúe y emplace a M artín en el barrio de La Boca. $\mathrm{N}$ i que gran parte de las conversaciones que mantiene con los entrañables M artín D 'Arcangelo, T ito o Bucich se desarrollen en este barrio 0 en torno a loas y nostal gias sin fin por los goles del famoso equipo de fútbol 
nacido en este barrio: Boca Juniors. Por supuesto, no lo es que Sobre héroes y tumbas (1961) comience en el parque Lezama. Según se cree, fue en este paraje donde Pedro de $M$ endoza y sus compañeros arribaron a Argentina, y su estatua se cierne amenazante para todos aquellos que decidan pasear por el parque. Es aquí donde supuestamente fue fundada Buenos Aires y donde el hombre occidental llegado a este territorio se encadenó para siempre a su destino americano. Y es desde aquí desde donde habría de partir a descubrir el oro inexistente de la Patagonia, aquella ciudad de los Césares de la que le hablará A lejandra a M artín. Es también el lugar donde lo americano comenzó a descubrir a lo occidental a través de un diálogo cegado a dos frentes que terminaron, finalmente, con la raíz indígena de América en Argentina. Es el término que enmarca el inicio del destierro, del descubrimiento de lo americano y de la implantación del pecado original argentino. Y es, por tanto, desde este emplazamiento simbólico, el parque Lezama, desde donde habría que comenzar el camino de redención del hombreargentino. D esdela raíz misma de su destino solitario semejantea la de aquel joven muchacho, $M$ artín, que se pregunta por el sentido de la vida al tiempo que mira la estatua romana de Ceres, la gran madre de la fertilidad, tan rígida ahora como todo su cuerpo de adolescente.

Por tanto, el trayecto de $M$ artín habrá de ser un recorrido espiritual cercano a la vida y al ejado de la tentación malévola de la posesión que lepermite comenzar a real izar el trasvase C aín-C risto y terminar de forjar el círculo de redención que se cierra con $M$ arcelo, el $C$ he G uevara y queencuentra su último sentido en la actuación y mensaje final de Sábato como personaje integrado en Abaddón el exterminador (1974). Por ello, si El túnel (1945) o La fuente muda (1947) eran retratos del infierno en los que no se atisbaba más que una débil esperanza final, Sobre héroes y tumbas representa un tránsito hacia el purgatorio que es el territorio donde se juega habitualmente la vida del hombre, siendo una novela donde los "otros" aparecen más humanizados. Este purgatorio y posible ascenso a un futuro paraíso o promesa de una Argentina unida a su destino americano, se realiza exactamente, se ve posibilitada, como ya hemos dicho, desde La Boca, forjando una simbología de reminiscencias claras.

Como sabemos, es La Boca un espacio que el hombre occidental en el destierro americano consiguió robarle a la naturaleza americana. Efectivamente, en el siglo XVIII, La Boca del Riachuelo era una extensión desolada, ya que las características de su terreno en ese entonces era pantanoso (predominaban los zanjales y los juncales). Y no fue hasta 1807, justo antes de que la nación argentina librase la lucha por su independencia, queel barrio nacería en los márgenes del Riachuelo, instalándose en el mismo un pequeño astillero y una pulpería. Así, desde 1860 y la llegada masiva de inmigrantes a la Argentina, se produjo el primer parcelamiento de los terrenos de este barrio que a partir de 1890 se 
convirtió en emblema, casa y al bergue de los millares de europeos (en su mayoría genoveses-italianos) que vinieron a radicarse definitivamente en Argentina.

Por tanto, si al go hemos de destacar de la construcción de este barrio es que es tal vez el único espacio real construido positivamente por el hombre occidental en Argentina. El europeo venido de América se encontraba en las faldas de la tierra preparadas para construir la ciudad o el campamento, como subrayara M artínez Estrada (1983). La ciudad se fundaba transitoriamente confiando en el retorno a Europa con los bolsillos repletos de oro. Y cuando la vuelta se hacía imposible, la ciudad comenzaba a cerrarse sobre sí misma para huir del peligro indígena, la terrible sensación del destierro y el ojo vigilante del D ios occidental del que se pretendía huir para negar la terrible verdad: el destierro cainita.

Sin embargo, en la barriada de La Boca y gracias a los esfuerzos de los desterrados por encontrar una nueva salida al puerto y un espacio habitable, se consigue forjar un espacio real con una dirección y sentidos diferentes a la de la mayoría de las construcciones de Buenos Aires y otras ciudades de la Argentina. En La Boca el hombreno niega su condición cainita. Al contrario, la afirma. N 0 serecuesta ciego sobresí mismo, el exterior dela vida y su destino exiliado como en tantos barrios de Buenos Aires o aquella artificiosa y afrancesada Recoleta por donde paseaban Castel y M aría. Se encuentra orgulloso de la misma. Y si, en su sentido negativo, esta afirmación amenaza fundar la tierra argentina a partir de la violencia y predice ya la posterior lucha con las armas 0 a través del balón (gracias al famoso duelo Boca-River) con el sempiterno enemigo abélico, en su sentido positivo, indica queel hombreargentino al fin reconoce su destierro. Y es gracias a este reconocimiento del destierro como ha sido capaz de forjar un espacio queno existía antes y queni siquiera era transitado por losindígenas, pues estaba sumergido en el lodazal, para construir una edificación, una barriada abierta a cualquier emigrante y no excluyente construida con el esfuerzo de toda la comunidad. Se construye una edificación para habitarla siempre. Se concede un sí al exilio. Se funda la verdadera $\mathrm{H}$ enoc y se plantan los cimientos de una ciudad en la que el extranjero sea siempre bienvenido, nunca sospechoso. Pues en La Boca se sabe que el hombre está obligado a errar, pero también necesitado de vivir en sociedad para encontrar un sentido a su vagar sin descanso.

Por ello, no resulta extraño que haya sido en los parajes de este barrio donde se suponga que empezaran a escucharse las primeras cantinelas de lo que luego sería el tango. Y quela cél ebre calle quelo corona, Caminito - en verdad, decepcionante para todo aquel que no pueda entender el sentido simbólico que encierra- , como su mismo nombre indica, refiera que la errancia de tantos emigrantes puede labrarse al fin un camino en Argentina. Un camino que siempre habrá de construir andando, caminando, a través del canto, de este lastimero y 
furtivo tango que recuerda las penas del destierro occidental. Pero que, a la vez, y una vez que los hijos de Caín han entendido el sentido de su caída, no la han negado, permite empezar la vida de nuevo. Reconstruirla y levantarla desde el fango.

Pues esto es La Boca y por lo que sospecho que, conscientemente o no, Sábato situaría gran parte de las noches, vida y adolescencia de M artín en uno deaquellos cuartuchos de este barrio: un barrio queha surgido desdeel barro, el lodo y el agua borrosa y encharcada por los residuos de los barcos, para acoger a los errantes, a los caídos, a los que no niegan su cul pa, los caínes y olvidados de medio mundo. Una parte del cuerpo de la madre tierra Eva que sus hijos pacientemente han liberado del mar y las cadenas de piedras, para habitarla en paz.

Por tanto, es La Boca un lugar en que se demuestra que, a pesar de todos los pesares, el hombre cainita podría llegar a entroncarse y ensamblarse con el nue vo destino que le ha tocado vivir. Puede llegar a ser uno con América. Es ahí donde habita la esperanza. D onde duerme $M$ artín. D onde las raíces del árbol castrado americano, como indica M aría Zambrano, "negadas a la función de soportar peso" desdela muerte delos indígenas, comienzan a "enredarse" con el cuerpo de los emigrantes hasta crear "un cuerpo nuevo, cuerpo prometido que se alza sostenido por la docilidad de su ráiz" (Zambrano, 1993: 62), permitiendo a América ser madre de un hombre redimido.

D e hecho, el barrio de La Boca ha de significar para M artín -y para cientos deemigrantes más- un centro maternal desdedonde comenzar a forjar vital mente una resistencia positiva y espiritual contra el poder del mal, de la materia, sin que la misma sea negada sino trascendida gracias a la construcción a partir dela misma materia de una casa o barrio desde donde poder resguardarse de su desamparo.

Sin embargo, hay un aspecto en el comportamiento de M artín que no ha de pasarnos desapercibido y es su rechazo desmedido a la materia o a lo materno. Lo cual es lógico si entendemos que la madre de M artín quiso expul sarlo de su vientre, abortar, matar al hijo que contenía en su interior y que su desahuciado padre vive resignado a su maligna suerte de pintor fracasado y es incapaz de ejercer una acción positiva que otorgue vitalidad a su hijo. El mismo M artín referirá de su madre en muchos momentos de la novela: "M i madre es una cloaca". Y, por ejemplo, encontraremos múltiples pasajes que nos ofrecen una explicación de su desmedido anhelo de espiritualidad que tanto atrae a Alejandra a partir del rechazo a esa madre:

Su madre (pensaba), su madre carne y suciedad, baño caliente y húmedo, os- 
cura masa de pel o y olores, repugnante estiércol de piel y labios calientes. (... ) pero él había dividido el amor en carne sucia y en purísimo sentimiento; en purísimo sentimiento y en repugnante, sórdido, sexo que debía rechazar, aunque (o porque) tantas veces sus instintos se rebelaban, horrorizándose por esa misma rebelión con el mismo horror con que descubría, de pronto, rasgos de su madrecama en su propia cara. Como si su madrecama, pérfida y reptante, lograra sal var los grandes fosos que él desesperadamente cavaba cada día para defender su torre, y ella como víbora implacable, volviese cada noche a aparecer en la torre como fétido fantasma, dondeél se defendía con su espada filosa y limpia (Sábato, 2000: 210).

Lo que significa que en M artín se libra una batalla fundamental: la aceptación o no de la realidad, de la condición cainita y la caída en aquella madre tierra americana repleta de lodazales, barro y sangre y que, siendo al bergue de tantos occidentales, se mostró, al mismo tiempo furiosa, cuando éstos le manifestaron su desprecio, cuando la entendieron y usufructuaron el fruto de su vientre como si fuera una prostituta que jamás podría regalarles el calor sentido en el seno de su madre occidental. Por ello es M artín - sometido a sus dos madres, la real y la americana- un hombre espiritual pero, sin embargo, al principio del libro, incapaz de ejercer acción positiva alguna. Porque $M$ artín vive en su seno una culpa todavía no trascendida. La culpa que todo cristiano siente al comprobar que la madre tierra, la madre nuestra no es espiritual y pura como la entendiera el agustinismo, sino que está bañada por el pecado, es real, emite flujos libidinales. Esto es, M artín se encuentra, utilizando palabras de Rozitchner (2001), repleto de culpa ante la ley sentida de la madre. Lo que para R ozitchner se produce en el cristianismo - en una sentencia que debemos entender para comprender el proceso sufrido por muchos emigrantes llegados a América-:

cuando el hijo, yendo a su encuentro cobijante para guarecerse y al mismo tiempo despertar las fuerzas adormecidas de sus pulsiones corporales sometidas en el patriarcado, experimenta al mismo tiempo la angustia de ser devorado ante la M agna M adre, y entonces pretende huir de ella y distanciarla (Rozitchner, 2001: 329).

Por esta razón, hemos de entender que $M$ artín acaso no haya tenido relaciones sexuales hasta la llegada de Alejandra a su vida y, desde luego, no haya penetrado en la historia de su país, pues esto supone aceptar que la madre tierra que le habita es América, mezclarse con el lodo americano y fango a partir del queseconstruyó el barrio deLa Boca, cuyos sentidosúltimos han de escapársele a $M$ artín al principio del libro. Pero como nos ha enseñado la gnosis, este desconocimiento sólo puede terminar en futura paralización, esclerosis, únicamente 
puede permitir que M artín como muchos de sus compatriotas sigan siendo manejados y vivan como aquellos seres que observa Bruno en los parques, totalmente separados, sin comunicación alguna entre los mismos, débiles. Aquellos "millones de habitantes que parecían ambular por Buenos Aires como en un caos, sin que nadie supiera donde estaba la verdad, sin que nadie creyese firmemente en nada" (Sábato, 2000: 270).

De hecho, como nos comenta lúcidamente Rozitchner, "el emperador Constantino" percibió "astutamente" en la época romana "que la nueva religión", el cristianismo, podía "aparecer cumpliendo subjetivamente esa tarea de protección imaginaria en cada súbdito, transformando la huida ante la madre en la que se buscó refugio en un encierro más absoluto todavía, al transformar a los dioses externos en un Dios interno que, bajo el complemento del modelo del crucificado, los" controlaba "desde adentro" (Rozitchner, 2001: 329). Pues eran los propios individuos, como M artín en Sobre héroes y tumbas, quienes censuraban sus propios actosy, en su necesidad de mantenerse puros y castos tal y como querían imaginar a la madreideal fecundada únicamente por el espíritu, no eran capaces de emitir acción positiva contra el I mperio romano, de penetrar en los misterios que habían desembocado en la llegada al poder del César pues esto suponía introducirse, ser partícipes y testigos de una historia de sangre'. César que, en el caso de la sociedad argentina, no era otro que Perón quien, sin embargo, olvidando la lección de Constantino, se cegó en su lucha final, una vez muerta Evita, contra los privilegios y derechos de la I gl esia C atólica lo que, sin duda, como sabemos, precipitó su caída del gobierno argentino².

Por esta razón, y siendo M artín un personaje que ha de permitir entender cómo se puedellegar a construir una verdadera patria unida en Argentina, ha de

${ }^{1}$ N os dice León Rozitchner (2001: 412) en una reflexión que ha de servirnos para profundizar más en el cisma producido en M artín y su carácter que deberá aprender a trascender: "Con el cristianismo, se dice, la moral se profundiza: debemos ser buenos no por la amenaza externa, sino por elección interna. $Y$ entonces se acude a una muerte que amenaza ahora desde adentro, a una amenaza más profunda: a la ley interna del corazón circuncidado. La muerte debe encontrar un asiento vivo, siempre presente como amenaza interna, en nuestro propio cuerpo. Nos construye como sujetos aterrorizados desde el surgimiento de la pulsión primaria y nuclear reprimida. $\mathrm{N}$ siquiera nostienta ya la posibilidad de enfrentar la ley: matamos voluntariamentela pulsión misma". Ibíd, p. 412.

Nos indican Floria y Belsunce (1992: 427) de las medidas queel Gobierno peronista antes de su caída tomó sobre la I glesia Católica: "El 27 de septiembre de 1954 una ley sobre asociaciones retira la personería jurídica 'a las asociaciones constituidas sobre la base de una religión, de una creencia, de una nacionalidad, de una raza o de un sexo'. EI 2 de diciembre se suprime la Dirección General de Enseñanza Religiosa. (... ) El 29 se reforma la ley de profilaxis social permitiendo el ejercicio de la prostitución. La I glesia que había gozado de los favores oficiales del régimen desde el 43 , comienza a conocer desdeentonces el asedio y la hostilidad. El régimen 'sacraliza' el culto a Evita y el 13 de mayo de 1955 es abrogada la ley de enseñanza religiosa". 
penetrar en los misterios ocultos y la historia velada que construyó Argentina. Esa será la única acción positiva realizable para que la historia pueda llegar a cambiar y que M artín comience - como muchos de sus compatriotas- a entender el porqué de su situación y aceptar el destino americano. Y, de esta manera, al tiempo que $M$ artín comienza a introducirse en la historia de sangre, mentiras y luchas ocultas que forjaron el país argentino que hasta ahora le había sido velada, deberá asistir también a los últimos suspiros del Gobierno de Perón y, por supuesto, a la lucha sin piedad entre los peronistas y antiperonistas por hacerse con el control de la Casa Rosada.

Por otra parte, es claro que el recuerdo de cómo se forjó esta prisión en donde $M$ artín se encuentra y, por tanto, el aprendizaje de cómo salir de la misma, la llave que abre las puertas de la realidad será para el joven muchacho, Alejandra3.

Alejandra le muestra el camino. Le enseña el mal sin ambages. Le da a beber el cuerpo de su patria y, ofreciéndose a M artín como perverso demonio que Ileva implantada la semilla del mal en su seno, le muestra asimismo cuál es el camino que ha de seguir para salvarse. El camino contrario a su estirpe, donde late la sangre de aquellos conquistadores judeo-cristianos, hijos de la nueva Israel, que como H ernandarias, tal y como le relatará a M artín, se encuentra presenteen la raíz de su familia: H ernandarias fueel "antepasado delos Acevedo" y en "1550 hizo la expedición en busca de la Ciudad Encantada" (Sábato, 2000: 204).

Es así. D iciéndole la verdad a M artín, obligándole a recordar, ofreciéndose como contra-ejemplo y, al mismo tiempo, como jugo tentador que es necesario desterrar, que Alejandra comenzará a expiar su falta, intentará vencer a su propio dragón. Es también la manera que utiliza Sábato para empezar a desvelar la historia apócrifa de la Argentina y mostrarla a sus compatriotas. Es ella quien le introduce en los secretos de la carne, la violencia, el misterio de todo sacrificio y le señala hacia dónde debe conducir su destino. $\mathrm{H}$ acia la ciudad encantada del alma, hacia el Toboso y la gloriosa D ulcinea pero también y, sobre todo, al frío mortal de la Patagonia, sus volcanes y tierras, la carnal América donde el oro que ha de encontrar es el más valioso y capaz de tranformar todas las cosas: el espíritu real de América, la madre y la mujer que ha de aceptar, comprender y por la que ha de luchar. La antigua prostituta cuyo rédito se guardaba con celo

\footnotetext{
${ }^{3}$ A modo de ejemplo, se nos dice en Sobre héroes y tumbas (Sábato, 2000: 270): "y todo giraba vertiginosamente en torno de la figura de Alejandra, hasta cuando pensaba en Perón y en Rosas, pues en aquella muchacha descendiente de unitarios y sin embargo partidaria de los federales, en aquella contradictoria viviente conclusión de la historia argentina, parecía sintetizarse, ante susojos, todo lo que había de caótico y de encontrado, de endemoniado y desgarrado".
} 
entre los muros de los torreones de C astilla y que se ha de aprender a amar. Con sus grandes defectos pero también sus grandes virtudes. D esde sus caminos destrozados, vías sin rumbo y salvajes fronteras que amenazaron a los primeros hombres que la visitaron y todavía parecen volverse vigilantes a contemplar el paso de los nuevos visitantes hasta los parajes envueltos en tergal, las bellas cascadas y los paisajes verdaderamente paradisíacos que los cegados hombres de Buenos Aires con la vista vuelta hacia atrás, Europa, son incapaces de descubrir.

$Y$, en este sentido, Alejandra-sobre la que, como en el seno de toda mujer, está depositado el papel de engendradora y, por tanto, del misterio de la vida, del conocimiento- es la reveladora de la composición de este mundo de tinieblas en que el gnóstico se encuentra atrapado, de la construcción del país argentino donde $M$ artín sufre su destino. Ella le muestra el camino de la libertad y, como la serpiente a Adán y Eva, a través de su sexo le muestra el camino para al umbrar la vida pero, asimismo, la muerte; es quien le abre los ojos para que compruebe en qué degenera la vida del hombre cuando éste se aparta de la ley divina o se cree merecido portador de la misma.

D esde este punto de vista, nada más adecuado que conocer la historia de la familia O Imos. Según nos informa Lilia Dapaz-Strout (Vázquez Bigi, 1985: $151)^{4}$, el olmo fue el árbol que Virgilio situó en en el dominio subterráneo e infernal de Plutón y es un signo preclaro que permite entender qué es lo que sucede al hombre cuando decide imponer su voluntad por encima de la ley. El mismo nombre angl osajón del iniciador de la línea de los 0 Imos, Patrick y más tarde Patricio, se relaciona etimológicamente con pater y patria. Pues son ellos, los hombres occidentales, esta familia que basó su antigua y extensa fortuna económica en el dominio de la tierra, los padres de este infierno en que ha degenerado Argentina. Q uienes elevaron su voz por encima del creador y decidieron imponer la ley rapaz del oro.

Es así como M artín entra en el tiempo de la historia. Pues la historia aparece en la vida del hombre gracias a la caída pero, sobre todo, a la reproducción. El nacimiento de Caín y Abel. Aunque, en realidad, para la cultura judía no será hasta la llegada de A braham y, sobre todo, las tablas de la ley concedidas a M oisés, cuando esta vida histórica comienza a forjarse trascendentemente. $Y$ si el génesis de la Argentina fue el tiempo del oro, de la mentira y del paraíso que jamás existió y por cuya promesa tantos hombres se vieron encerrados en América, el tiempo histórico nació con la Independencia. Lo que debeaprender a ser $M$ artín: independiente. Forjar una personalidad propia como aś lo intentara el país argentino en los míticos tiempos de las luchas entre unitarios y federales, a cuyo conocimiento llega gracias a Alejandra. Una guerra sin ley alguna entre dos bandos que como los partidarios Saúl y David lucharían, tal y como lo 
muestra Sábato en la novela, por hacerse finalmente con los destinos del pueblo judeo-cristiano en el destierro americano.

Por ello, será tras su desencuentro con Alejandra en el Adam y la terrible despedida entre ambos, cuando $M$ artín entrará de golpe en la historia de su país. Se introduce para siempre e irremediablemente en su historia como si traspasara un espejo. Ya puede comenzar su travesía solo.

Precisamente -y por fuerza de un azar objetivo siempre riguroso en el caso del país argentino- fue el mismo día que Baistos mordió la carne de su hermano, el día del Corpus C hristi, cuando la rivalidad y la lucha entre peronistas y antiperonistas se mostró de una manera clara y precisa. Pues fue éste el día elegido por el antiperonismo para desafiar al régimen deffilando por las calles deBuenosAires. Y sería esta fechala detonante, una vez queel gobierno peronista envió al exilio al obispo auxiliar de Buenos Aires, monseñor M anuel Tato, de la consiguiente excomunión de Perón que la Santa Sede realizaría el 15 de junio.

D e esta manera, una escuadrilla antiperonista provocará el asalto de la Plaza de $M$ ayo motivando que esa misma noche los partidarios del general Perón se lancen a la quema de templos católicos. Ese día fue 16 de junio. Y es también el día que M artín comienza a realizar su travesía histórica en el presente real de la Argentina. Y resulta muy curioso que la escuadra que inundara de fuego, como predijera Barragán, la plaza de la nueva Babilonia, estuviera destinada, en principio, a homenajear a Eva Perón. Pues este hecho pone aún más de relieve la importancia de que $M$ artín y un peronista se animen en la escena que relata los sucesos de aquella noche de odio magníficamente descrita por Sábato, a salvar a la Virgen de los $D$ esamparados. Es ella la madre espiritual, la luz que trae consigo el recuerdo del pleroma y es la estatua que no está empantanada en flujo vaginal alguno y donde encuentra $M$ artín la pureza ansiada que su madre no ofrece. Sin ser cuerpo, sin ser labios, sin ser carne, está al ejada de todo mal. Ella no puede corromper ni ser corrompida. N o es M aría I ribarne quien estaba atada de manera fatal como Alejandra a la materialidad corporal. No es América. Es el recuerdo de Europa. D e los barcos que se fueron para no volver. No tiene culpa ni pecado. N o tienela huella del padreen su interior. Selo diceun peronista, un cabecita negra, a una señora indignada ante el sal vaje comportamiento de las hordas de Perón y que abrazará los pies retorcidos en sangre de un C risto: " ¿Y qué culpa tiene la Virgen de todo esto?" (Sábato, 2000: 317).

Al contrario, Evita fue mortal. M urió. Era el pecado. El lacerante recuerdo de la mortalidad. La madre que dejó a sus hijos perdidos en el destierro. De nuevo, desamparados. Divididos. La mujer de baja extracción. La prostituta. América. La mujer que rompió la ley y amó al padre y al marido. Q uien provocó la ruptura inicial del primer anthropos andrógino que fuera el Adán. La 
primera división. Las dos fuerzas, Caín y Abel, que pugnan por imponer el reino de lo materno o de lo paterno. $Y$, por ello, resulta muy ajustado que fuera el día dedicado a homenajearla, cuando las potencias peronista y antiperonista enfrentadas por la posesión de la tierra y, en verdad, siendo esclavizadas de nuevo por un solo Dios (el diablo), colisionasen de nuevo sobre el sangriento suelo argentino.

En este sentido, será fundamental para la futura transformación de un M artín ya para siempre separado de Alejandra y atisbando la terrible potencia que esconde el mal, encontrar el signo de lo mariano en el mundo material. Pues este gesto significará unir a Eva y $M$ aría, que es el trasvase que todo hombre ha de hacer para atisbar el camino de la confianza, la fe en este mundo. Significa completar una figura que a $M$ artín sólo le será dada atisbar y unificar definitivamente cuando decida abandonar para siempre la idea de su suicidio gracias a la aparición de H ortensia: M aría M agdalena. La mujer que, según al gunas versiones apócrifas, Ilegó a conseguir que el C risto se abrazara a la materia. Pecase. Se abrazara a la madre tierra en un abrazo terrenal. Aquella peligrosa M aría M agdalena, quien como supo comprender Proust mientras mecía sus labios en su leche, en verdad, recuerda que el nuevo hombre, el Cristo redimido o el Caín creador, sólo podrá llegar cuando pueda trascender la materia a través de lo espiritual y viceversa. En verdad, la mujer que complementa la simbólica escena de la muerte de C risto. La figura que viene a integrar la pura luz de la Virgen y le otorga la oscuridad necesaria para que ésta brille, la luna que vienea relevar al sol en su duelo y cuidado del C risto muerto en la cruz, la sombra que cuida que el cuerpo de M aría no se desvanezca de dolor y el cuerpo de su hijo muerto, ensangrentado, caiga en sus brazos para emitir una resplandeciente luz: la luz del conocimiento, la gnosis.

En suma, la mujer que ayuda a comprender el pecado. Q uien enseña que sin pecado no hay vida como sin el mal no podría existir la posibilidad de acceder al bien, al verdadero conocimiento. A ese misterio de la creación que recostaría aún más a un anciano Proust - mientras la peste de la guerra hacía sus estragos a principios del siglo XX - sobre su lecho para terminar de hilvanar la perdida y escondida historia de su origen y recobrar el tiempo perdido para siempre. Pues es ésta la mujer, la humi lde, la pecadora, la que le regal ará D iosa M artín cuando le reclame su presencia antes de decidir suicidarse o no.

Es M aría, la Virgen, la que reza por el C risto, pero es M aría M agdalena la que canta por él. Porque la Virgen recoge al niño que nunca se fue. El niño que estuvo prisionero en el mundo material pero ha vuelto a su estado puro, al pleroma. Unicamentereza para que el tránsito mortal pueda ser efectuado. Pero M agdalena canta para que Caín vuelva en sí. Canta para que siga viviendo, efectuando el tránsito vital. Aunque duela. Pero la vida es travesía y si ha decidi- 
do vencer al diablo, no arrojarse en la $G$ arganta del Diablo a la que se precipitara Lavalle con su gesto asesino, condenando al mismo tiempo a la nación argentina, es mejor vivir cantando. La música paraliza al demonio. Es la mejor compañera de Caín. Q uien le anima a seguir luchando sin armas por revelar la verdad de su historia, el engaño que sufriera por aquel terrible D ios.

La madre hecha únicamente de espíritu y sin rastro de cuerpo del padre en su seno vela por el muerto, por el retorno del hijo pródigo a su lecho que es siempre vuelta al seno materno hecho de espíritu en el cristianismo y disuelto en luz de sabiduría por la gnosis. En realidad, nunca había salido de la madre. Pero la M agdalena canta porqueella intenta reanimar al vivo, es la quecree en la resurrección porque es la que está más cerca de la vida. C risto no ha muerto. Estádurmiendo, con los ojoscerrados, aparentemente ciego como M artín, quien gracias al canto de Hortensia, a los llantos del niño, la visión del Cristo y su búsqueda de la verdad, sabrá cuál es el camino que ha de realizar ahora. El camino al revés del que realizara $\mathrm{H}$ ernandarias. Ir en busca del corazón de América. Así se lo señalará aquel Cristo que "tenía el pecho abierto como en una lámina Testut y mostraba su corazón con un dedo, en colores" (Sábato, 2000: 509). Esto es lo que debe hacer. M ezclarse con ella para siempre y renacer en alma nueva, reconocer a América, la tierra argentina, el sucio barrio de La Boca y loslabioscarnosos de su madre, "pues", como indicara M aríaZambrano (1993), "sólo hay propiamente madre cuando nace un cuerpo nuevo", un hombre nue vo que no tiene miedo de vivir, de la materia o el espíritu. Y esto será M artín al final de la novela. "Un cuerpo hacia la luz que cumple su promesa" y se atreve a mirar heroicamenteal ciclo vida-muerte deestecontinente a la cara, historizando y des-historizándolo para engendrar la vida nueva que permita la existencia de una tierra fértil, de una verdadera madre que, como bien supiera la pensadora española, "sólo" existe "en el cumplimiento de una promesa de la vida a la luz" (Zambrano, 1993: 62, 63).

Es allí donde se encuentra el verdadero oro y no en La ciudad de los Césares que el padre del camionero que lo acompaña en su búsqueda, Bucich, fue a buscar aún en el siglo XIX. D onde se encuentra ese "país inexistente pero posible" (Sábato, 2000: 118) que dibujaba M artín en forma de periódico en el parque Lezama. Y para hacerlo posible es necesario romper para siempre con el círculo del eterno retorno de lo mismo que siempre vuelve. El ciclo burgués del trabajo diabólico al que se encuentra encadenado el hombre y del que sale, simbólicamente, para siempre $M$ artín regalando el anillo de poder que sella en su mano el dominio del orden imperante, a H ortensia.

Es entonces cuando, inconscientemente, M artín lo comprenderá todo. Aunque necesite de Bruno para poder terminar de reconstruir la historia infernal que le ha llevado al intento de suicidio y ha llevado a su país a una paupérrima 
situación. O bserva una foto de Evita y $\mathrm{Gardel}$, escucha las preguntas de $\mathrm{H}$ ortensia, "ino le parece hermoso M adreselvas en flor? ¿Y Caminito? (...) D espués están lasflores, los pájaros, los perros, quéséyo" (Sábato, 2000:510) y las dudas quele asaltaban sobrela posible emigración del al ma tras la muerte, se resuelven por sí solas.

Puede que el hombre no sepa hacia dónde camine. Puede que Argentina no tenga un camino trazado. Pero esto no debería ser motivo de desesperanza. Si bien no sabemos dónde va nuestra alma tras la muerte, al menos tenemos las piernas, este cuerpo y nuestra alma para moverla a través del mundo. Viajar no tendría por qué representar exilio. Podría ser también descubrimiento. C amino hacia el pleroma y la identidad americana. C aminito hacia D ios. D esde La Boca hasta la Patagonia pasando por Jujuy.

Al fin y al cabo, esto es lo que ya intentara el padre de M artín o los propietarios del M oscota: caminar a ciegas antes de dibujar una forma sobre el tapiz, buscar el origen. Incluso Castel o Carlos, a pesar del fracaso del dibujo de su enamorada que realizara este último. Y al guien debería darle sentido a su lucha. 0 , al menos, al guien debe realizar a ciegas en la vida el mismo camino que ellos real izaron a ciegas a través de la pintura. Buscar a D ios, su identidad, a través de los signos de lo americano. Ese es el camino que empieza a real izar $M$ artín una vez que no levanta las armas, se niega a quitarse la vida y acepta como madre a la prostituta americana que hasta entonces despreciaba o le causaba pavor: el camino de C aín a C risto que puede dar sentido al fracaso de su padre, de tantos hombres, ofrecerles val or sin necesidad dedesempuñar el puñal deFierro. Aquel cegado culto del coraje.

D ecía Joseph Campbell (1999) que el frágil héroe de nuestro tiempo y de todas las épocas está obligado a adquirir la suficiente "madurez para entender cómo las enfermas y enloquecidas tragedias de este vasto mundo sin escrúpulos adquieren plena validez en la majestad del Ser". Sólo así podrá trascender "Ia vida y su peculiar punto ciego" (C ampbell, 1999: 214) elevarse a contemplar el agua cristalina pre-bautismal del primer tiempo donde poder reconciliarse definitivamente con su padre. En suma, esto es lo que hace M artín una vez que ha merecido el amor de la mujer que, para Campbell (1999), era esencial para llegar a disfrutar esta vida como estuche que promete la eternidad. M artín se reconcilia con su padre y con sus antepasados y con un Dios desconocido que sabe que nunca podrá nombrar que se le apareció en forma demujer, mostrándolela justicia bendita a través de la que compuso la creación. Así, M artín - siguiendo en esto a Campbell (1999)- trasciende su pasado y olvida al fin su ego, siendo canal que posibilita la futura ll egada de C risto en los hombres, pues al "disolver totalmente todas sus ambiciones personales, ya no trata de vivir, sino que se entrega voluntariamente a lo que haya de pasarle; 0 sea que se convierte en anónimo. La 
Ley vive en él con su consentimiento sin reservas" (C ampbell, 1999: 217). H a podido trascender su Caín interior.

Lo que también significa que está abriendo una nueva vía para el destino de su pueblo, su país. Pues M artín, como todo héroe mitológico, según C ampbell (1999), "es el campeón no de las cosas hechas sino de las cosas por hacer" y por ello, "el dragón que debe ser muerto por él, es precisamente el monstruo del status quo: (... ) el guardián del pasado" (C ampbell, 1999: 217). El hombreque no tiene miedo de enfrentarse desnudo a los hielos de la Patagonia para que su corazón se derrita con la visión absoluta de la realidad que cobija de nuevo a los hombres al albergue de los mares. Un paso más allá de quienes necesitaron empantanar con su cegada imaginación los parajes patagónicos. Como sabía el pueblo israelí, entre el exilio y el éxodo hay una gran diferencia. La que hay entre recibir un nombre ya dado sin posibilidad de réplica y buscar el nombre que, en realidad, habría de pertenecernos.

\section{REFEREN CIAS BIBLIO GRAFICAS}

Campbell, Joseph. 1999. El héroe de las mil caras. Psicoanálisisdel mito. M éxico: Fondo de Cultura Económica.

Dapaz-Strout, Lilia. 1985. "Símbolos primordiales, mito e historia en Sobre héroes y tumbas", en Vázquez, A.M . Epica dadora deeternidad. Sábato en la crítica americana y europea. Buenos Aires: Sudamericana/Planeta, pp. 148-155.

Floria, Carlos y G arcía Belsune, A. 1992. Historia de los argentinos II. Buenos Aires: Ediciones Larousse.

M artínez Estrada, Ezequiel. 1983. Radiografía de la pampa. Buenos Aires: Editorial Losada.

Rozitchner, León. 2001. La cosa y la cruz. Cristianismo y capitalismo. (En torno a las Confesiones de San Agustín). Buenos Aires: Editorial Losada S.A.

Sábato, Ernesto. 2000. Sobre héroes y tumbas En 0 bra completa. Narrativa. Buenos Aires: Editorial Planeta Argentina S.A. Seix Barral. Segunda edición.

Zambrano, M aría. 1993. La razón en la sombra. Antología del pensamiento de M aría Zambrano. M adrid: Ediciones Siruela S.A. 